\title{
Implementasi User Autentikasi Berbasis SMS Gateway dan Mikrotik Hotspot Monitor di SMK Al-Farisi Kecamatan Leles
}

\author{
Mamay Syani ${ }^{1}$, Shandy Tresnawati ${ }^{2}$, Dini Rohmayani ${ }^{3}$ Kevin Junia Rizqi ${ }^{4}$ \\ Jurusan Teknik Komputer dan Informatika, Politeknik TEDC Bandung \\ Jl.Pesantren-Politeknik, Kecamatan Cimahi Utara, Kota Cimahi Jawa Barat, Indonesia \\ msyani@poltektedc.ac.id ${ }^{1}$, shandy.tresnawati@poltektedc.ac.id ${ }^{2}$, dinirohmayani@ poltektedc.ac.id ${ }^{3}$ \\ kevinjuniarizqi@gmail.com ${ }^{4}$
}

Diterima : 8 Maret 2021. Disetujui : 22 Mei 2021. Dipublikasikan : 30 Mei 2021.

\begin{abstract}
SMK Al-Farisi Leles currently provides hotspot services that are an area where there is a wireless internet connection that can be accessed through laptops, gadgets and other devices that support the technology. With the hotspot in SMK Al-Farisi Leles, users can enjoy internet access in the hotspot area without having to connect to a cable. Hotspot in SMK Al-Farisi can be accessed directly by anyone, because the authentication system is still conventional, namely authentication that enters the password to be connected to the hotspot network, this often results in an unstable connection because there is no limit to be able to connect to the hotspot network so that people outside the school community who are in the hotspot area can be connected freely. Therefore, the author implements SMS gateway-based Authentication user and mikrotik hotspot monitor in SMK Al-Farisi where the user is required to request first to get a hotspot account via SMS with the provisions provided by the administrator. The results showed that this authentication system runs smoothly and can manage users connected to hotspot networks in a self-service using SMS gateway feature that is integrated with mikrotik hotspot monitor online with $100 \%$ server response.
\end{abstract}

Keywords: smk al-farisi, wireless internet, sms gateway, mikrotik hotspot monitor, authentication, request.

Abstrak - SMK Al-Farisi Leles saat ini sudah menyediakan layanan hotspot yaitu sebuah area dimana pada area tersebut tersedia koneksi internet wireless yang dapat diakses melalui laptop, gadget maupun perangkat lain yang mendukung teknologi tersebut. Dengan adanya hotspot di SMK Al-Farisi Leles maka pengguna bisa menikmati akses internet di area hotspot tanpa harus tersambung dengan kabel. Hotspot di SMK Al-Farisi dapat diakses secara langsung oleh siapa saja, karena sistem autentikasi-nya masih bersifat konvensional yaitu autentikasi yang memasukkan password untuk bisa terkoneksi dengan jaringan hotspot, hal ini sering mengakibatkan terjadinya koneksi yang tidak stabil karena tidak ada batasan untuk bisa terkoneksi ke jaringan hotspot sehingga orang-orang diluar masyarakat sekolah yang berada di area hotspot pun bisa terkoneksi dengan bebas. Oleh karena itu penulis mengimplementasikan user autentikasi berbasis SMS gateway dan mikrotik hotspot monitor di SMK Al-Farisi dimana user diharuskan merequest terlebih dahulu untuk mendapatkan akun hotspot melalui SMS dengan ketentuan yang sudah disediakan oleh administrator. Hasil penelitian menunjukan bahwa sistem autentikasi ini berjalan dengan lancar dan dapat mengelola user yang terhubung ke jaringan hotspot secara self service menggunakan fitur SMS gateway yang diintegrasikan dengan mikrotik hotspot monitor secara online dengan respon server $100 \%$.

Kata kunci: smk al-farisi, wireless internet, sms gateway, mikrotik hotspot monitor, autentikasi, request

\section{PENDAHULUAN}

Pemanfaatan teknologi informasi merupakan hal yang penting disetiap institusi Pendidikan. Institusi pendidikan seperti sekolah menengah kejuruan adalah salah satu tempat yang sangat memperhatikan perkembangan teknologi informasi, berbagai inovasi terus ditingkatkan untuk memenuhi kebutuhan kepada setiap orang di sekolah. Salah satu layanan yang sangat penting untuk memenuhi kebutuhan masyarakat di sekolah adalah fasilitas internet, dengan layanan internet maka akan membantu meningkatkan kegiatan belajar menjadi lebih baik karena menambah akses literature selain dari buku pelajaran dan modul sekolah [13].

SMK Al-Farisi Leles saat ini sudah menyediakan layanan hotspot yaitu sebuah area dimana pada area tersebut tersedia koneksi internet wireless yang dapat diakses melalui Laptop, Gadget maupun perangkat lain yang mendukung teknologi tersebut. Dengan adanya hotspot di SMK Al-Farisi Leles maka kita bisa menikmati akses internet di area hotspot tanpa harus tersambung dengan kabel. Layanan inilah yang dijadikan salah satu sarana untuk akses informasi bagi siswa, guru maupun karyawan, khususnya di dunia pendidikan yang 
mana diketahui sebagai acuan kemajuan teknologi informasi.

Hotspot di SMK Al-Farisi dapat diakses secara langsung oleh siapa saja, karena sistem autentikasinya masih bersifat konvensional yaitu autentikasi yang hanya memasukan password untuk bisa terkoneksi dengan jaringan hotspot, hal ini sering mengakibatkan terjadinya koneksi yang tidak stabil karena tidak ada batasan untuk bisa terkoneksi ke jaringan hotspot sehingga user diluar masyarakat sekolah yang berada di area hotspot pun bisa terkoneksi dengan bebas [5].

Oleh sebab itu diperlukan sistem autentikasi, user management dan monitoring jaringan hotspot untuk memaksimalkan dan menjaga layanan tersebut, sistem ini yang nantinya akan menjadi pusat pengotrolan user karena sebelum user bisa menggunakan koneksi internet, user diharuskan proses mendaftar terlebih dahulu untuk mendapatkan akses dengan jaringan hotspot. Sehingga dengan demikian, administrator dapat lebih mudah melakukan monitoring user yang terhubung ke jaringan hotspot [14].

Berdasarkan masalah tersebut dibuatkan solusi dengan mengandalkan user autentikasi menggunakan SMS Gateway, dengan adanya sistem autentikasi ini dapat menjadikan akses internet wireless di sekolah menjadi lebih aman dan mempermudah administrator dalam memanajemen user yang terubung ke jaringan hotspot sekolah [8] [9].

\section{METODE PENELITIAN}

Metode yang diterapkan dalam penelitian ini adalah metode Network Development Life Cycle (NDLC), yaitu Analysis, Design, Simulation, Implementation, dan Monitoring, Metode ini digunakan untuk menganalisis dan merancang user autentikasi berbasis SMS Gateway di SMK Al-Farisi Leles [1].

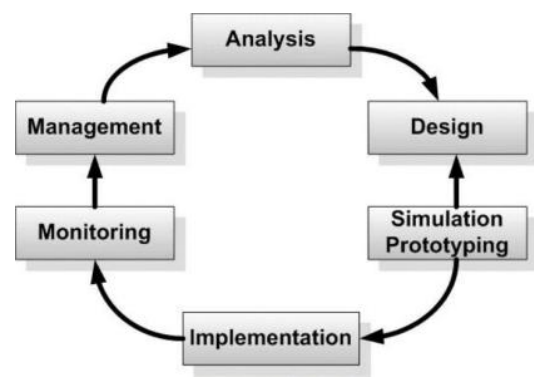

Gambar 1. Alur NDLC

\section{Analysis}

Pada tahap ini dilakukan analisis terhadap perangkat dan keamanan yang digunakan pada jaringan wireless di sekolah. Analisis dilakukan dengan melakukan observasi untuk mendapatkan data-data dan masalah yang ada dalam sekolah, dan memberikan usulan pemecahan masalah.

\section{Design}

Pada tahap ini perancangan terhadap konfigurasi yang akan dilakukan pada SMS Gateway dan router mikrotik dan setup server software mikrotik hotspot monitor serta parameternya sesuai dengan usulan pemecahan masalah.

\section{Simulation}

Simulasi perancangan user autentikasi dilakukan menggunakan perangkat handphone dengan melakukan pendaftaran hotspot melalui SMS Gateway dan monitoring log di server.

\section{Implementation}

Melakukan implementasi hasil konfigurasi SMS Gateway dan server mikrotik hotspot monitor yang bekerja pada router mikrotik.

\section{Monitoring}

Melakukan monitoring terhadap user yang terkoneksi dengan jaringan hotspot.

\section{Management}

Membuat atau mengatur server SMS Gateway dan miktrotik server monitor yang telah dibangun berjalan dengan baik

\section{A. Analisis Sistem yang Berjalan}

Sistem autentikasi pada jaringan wifi yang digunakan di SMK Al-Farisi Leles adalah WPA/WPA2 PSK, sistem ini menggunakan password untuk masuk ke jaringan wifi. Sehingga tidak ada sistem yang dapat mengontrol user yang terhubung ke jaringan. Alur dari sistem yang berjalan dapat dilihat pada gambar 2 berikut [10] [11].

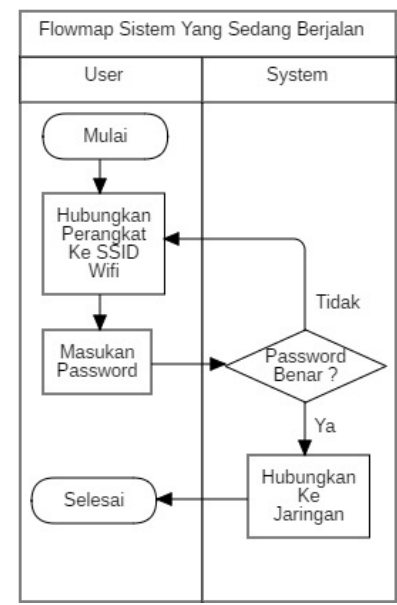

Gambar 2. Sistem yang sedang Berjalan

\section{B. Perancangan}

Berikut Flowmap dari sistem SMS Gateway autoreply pada sistem yang akan dibangun : 


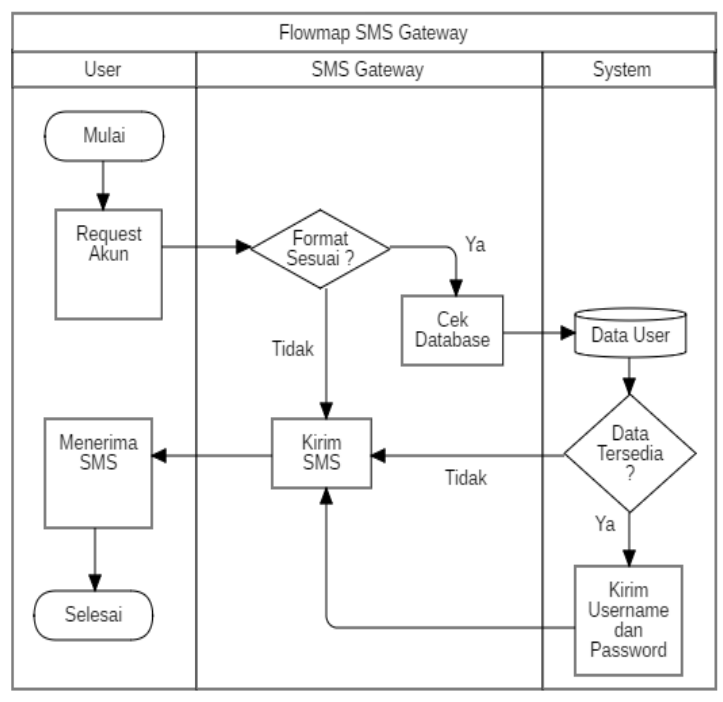

Gambar 3. Flowmap Sistem Autoreply

Berikut Flowmap dari sistem SMS Gateway autoreply pada sistem yang akan dibangun pada Gambar 4.

\section{Kebutuhan Hardware}

Perancangan user autentikasi berbasi SMS gateway ini akan menggunakan beberapa hardware sebagai berikut:

1. Mikrotik Router Board RB952ui Router OS Lisensi Level 4[15]

2. Modem GSM USB Dongle 2.0 Huawei

3. PC Dekstop

4. Network Interface Card Gigabit

5. Kabel UTP[7]

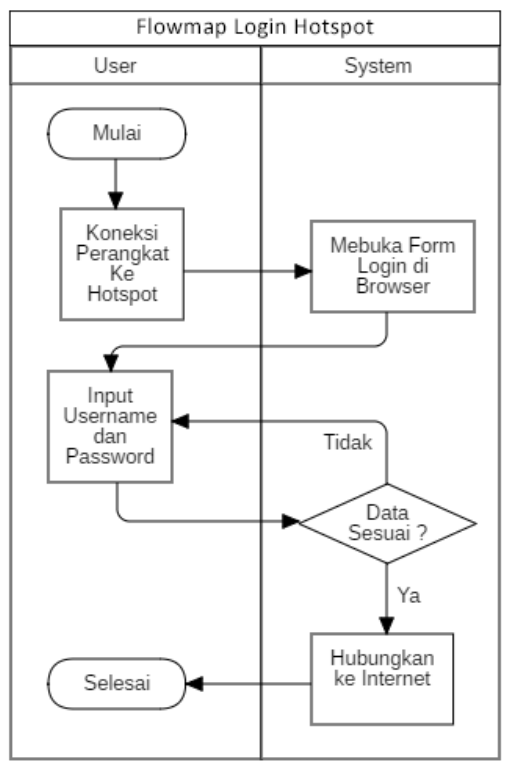

Gambar 4. Flowmap Login Hotspot

\section{Perancangan Software}

Kemudian beberapa software yang digunakan pada proses membangun sistem ini adalah:

1. Winbox[12]

2. Mikrotik Hospot Monitor (Mikhmon) [4][6]

3. Web Browser

4. Gammu 1.41 [2] [9]

E. Perancangan Sistem Autentikasi Berbasis SMS Gateway.

Setelah melakukan analisis dan perancangan sistem, tahap selanjutnya adalah merancang sistem autentikasi berbasis SMS Gateway ini semua kebutuhan sistem harus terpenuhi. Kebutuhan hardware dan software bertujuan untuk mengimplementasikan dan menguji sistem yang sudah dibuat [2].

\section{F. Menampilkan Aplikasi User Manager Mikrotik}

Dalam melakukan konfigurasi User Manager Mikrotik, ada beberapa halaman yang terdapat dalam aplikasi berbasis Web.

\section{Form Login}

Halaman ini menampilkan form login untuk admin melakukan login agar dapat melakukan manajemen hotspot, adapun tampilan login dapat dilihat pada gambar 5 .

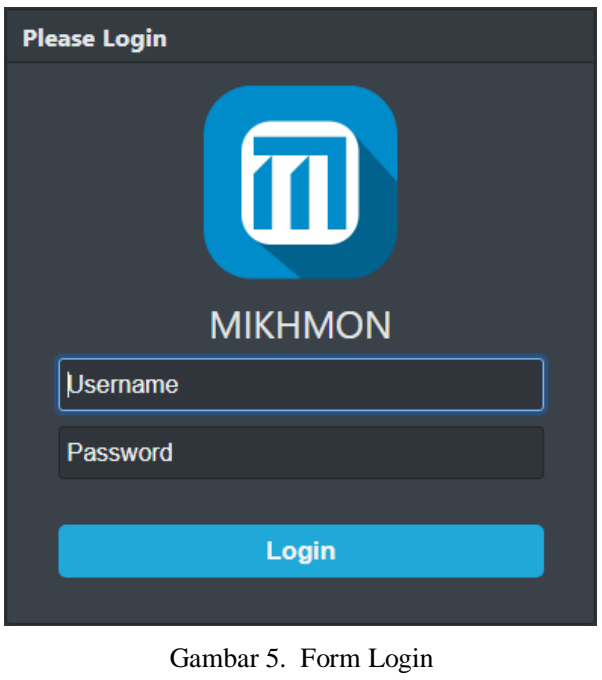

2. Halaman Admin Setting

Halaman ini menampilkan konfigurasi administrator seperti konfigurasi username dan password untuk login admin. Pada halaman ini juga menampilkan Router List yaitu koneksi antara aplikasi user manager dan mikrotik. Adapun tampilan dari admin setting dapat dilihat pada gambar 6. 


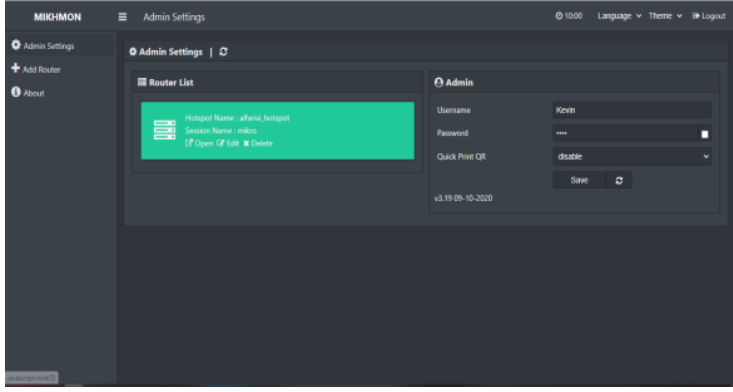

Gambar 6. Halaman Admin Setting

\section{Halaman Session Setting}

Halaman ini menampilkan form yang berfungsi untuk menghubungkan aplikasi User Manager dengan Mikrotik. Pada halaman ini administrator memasukan IP address, username dan password yang sudah dikonfigurasi pada Router Mikrotik. Adapun tampilan dari halaman session setting dapat dilihat pada gambar 7 .

\section{Halaman Dashboard Mikrotik}

Halaman ini menampilkan informasi tentang mikrotik yang sudah tersambung dengan aplikasi user Manager. Pada halaman ini juga terdapat informasi tentang user hotspot yang terhubung dengan mikrotik, jumlah user hotspot yang tersedia pada mikrotik, dan menu untuk generate user. Terdapat juga log dari user yang login ke hotspot. Adapun tampilan dari halaman dashboard mikrotik dapat dilihat pada gambar 8[9].

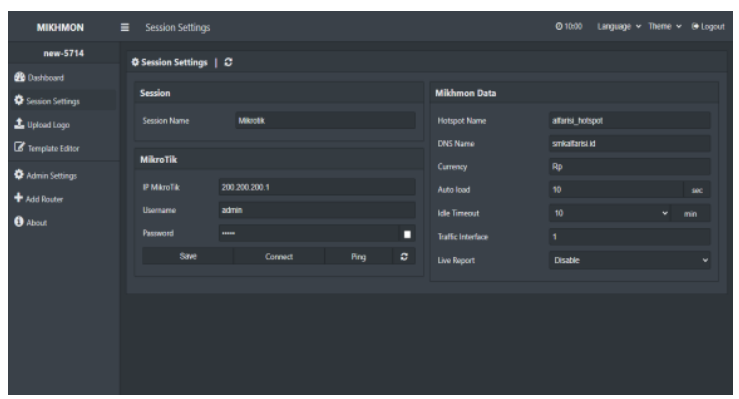

Gambar 7. Halaman Session Setting

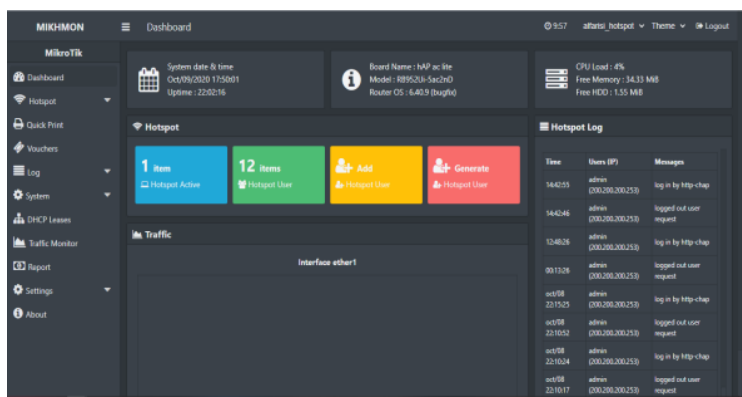

Gambar 8. Halaman Dashboard Hotspot Server

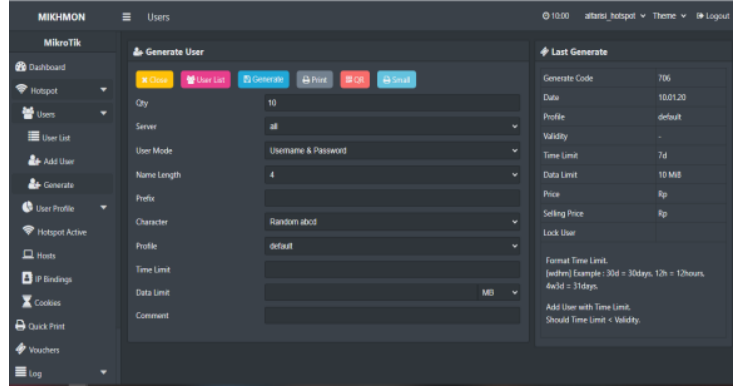

Gambar 9. Halaman Generate User

\section{Halaman Generate User Hotspot}

Halaman ini menampilkan form input yang berfungsi membuat user hotspot secara masal. Adapun tampilan dari halaman generate user hotspot dapat dilihat pada gambar 9 .

\section{Halaman User List}

Halaman ini menampilkan informasi tentang user hotspot yang sudah dibuat di menu generate user, pada halaman ini tersedia menu untuk print out username dan password, dan juga menu untuk mendownload data user dalam bentuk file CSV (Comma Separated Values). Adapun tampilan dari halaman user list bisa dilihat pada gambar 10 .

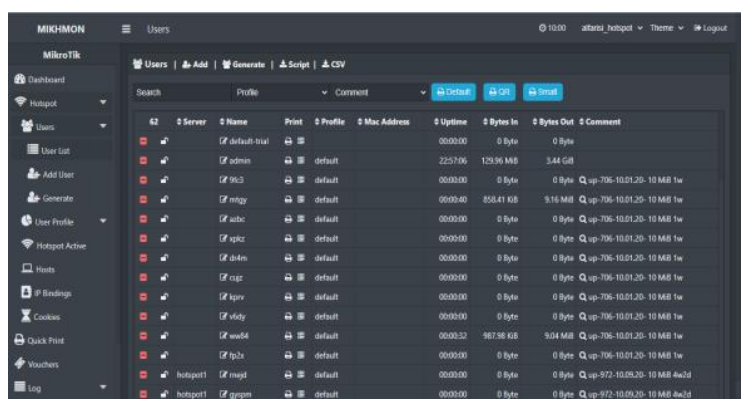

Gambar 10. Halaman List User

\section{Halaman Hotspot Active}

Halaman ini menampilkan informasi tentang user yang tersambung pada hotspot server. Adapun tampilan dari halaman hotspot active bisa dilihat pada gambar 11 .

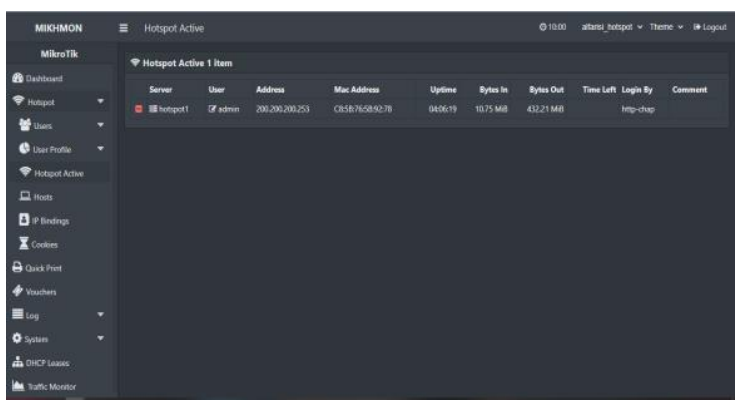

Gambar 11. Halaman Hotspot Active 


\section{Menampilkan Layanan Server SMS Gateway}

Ketika user melakukan proses request account, secara otomatis akan mendapatkan pesan berupa username dan password yang sudah digenerate di aplikasi User manager. Proses autoreply tersebut dikerjakan oleh server yang sudah dibangun menggunakan gammu dan web service menggunakan PHP. Untuk menjalankan proses autoreply, server gammu harus diaktifkan terlebih dahulu melalui Command Prompt seperti pada gambar 12[2].

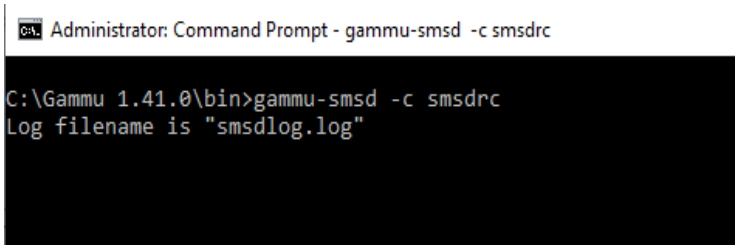

Gambar 12. Layanan Server Gammu

Pada gambar 12 tersebut menunjukan layanan Gammu sudah berjalan dan semua aktivitas yang terjadi pada server secara otomatis akan tersimpan pada file "SMSdlog.log" yang terdapat pada directory bin.

9. Menampilkan Layanan Hotspot

Ketika user menghubungkan perangkat ke hotspot server, secara otomatis akan terbuka halaman web untuk melakukan proses login, terdapat beberapa halaman pada proses ini sebagai berikut[8].

\section{Halaman Login}

Halaman ini menampilkan form input username dan password untuk tersambung ke layanan internet,. Adapun tampilan dari halaman login bisa dilihat pada gambar 13 .

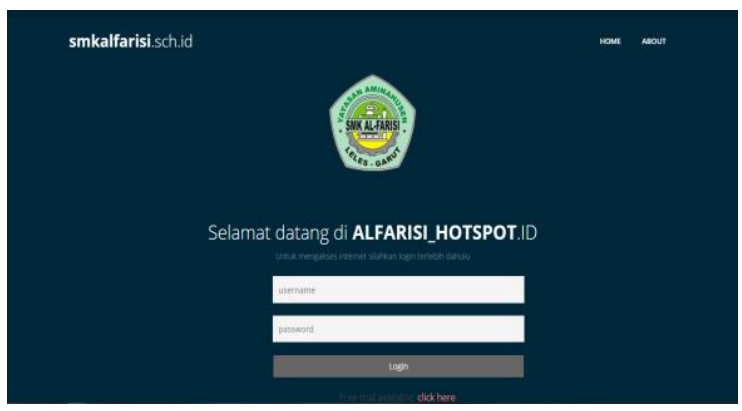

Gambar 13. Halaman Login Hotspot

\section{Halaman About}

Halaman ini menampilkan informasi tentang tata cara mendapatkan user hotspot melalui SMS. Adapun tampilan dari halaman about bisa dilihat pada gambar 14.

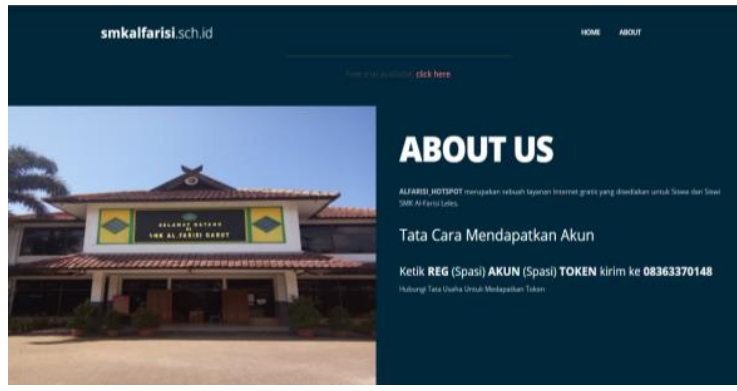

Gambar 14. Halaman About

\section{Halaman Status}

Halaman ini menampilkan informasi setelah sukses melakukan login, terdapat beberapa informasi diantaranya username, IP address, Mac address, kuota, dll. Adapun tampilan dari halaman status bisa dilihat pada gambar 15 .

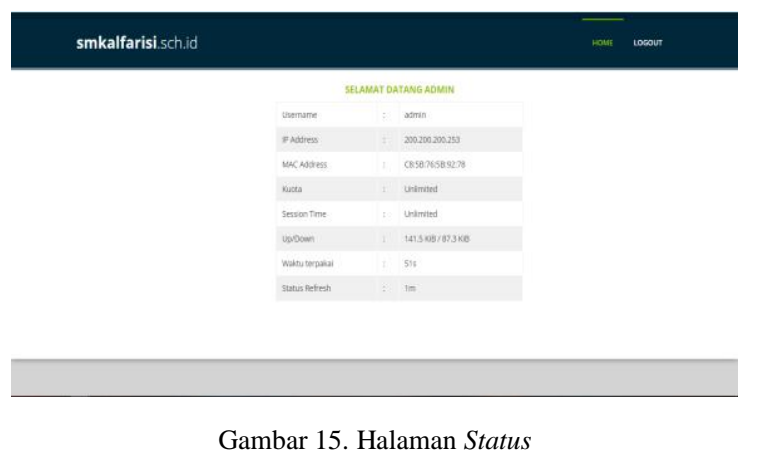

III. HASIL DAN PEMBAHASAN

\section{A. Pengujian Sistem}

Pada pengujian sistem ini menitik beratkan apakah sistem hotspot menggunakan user autentikasi berbasis SMS Gateway di SMK Al-Farisi telah bekerja sesuai dengan yang diharapkan. Pengujian dilakukan langsung oleh user dengan melakukan proses request akun, kemudian mengoneksikan perangkat ke hotspot dan melakukan login sesuai dengan akun yang diterima oleh user. Berikut adalah hasil dari pengujian sistem autentikasi berbasis SMS gateway dan mikrotik hotspot monitor sebagai server-nya.

\section{B. Pengujian Request Akun}

Proses pengujian ini dilakukan oleh user yang melakukan self-request akun melalui SMS dengan format REG ALFRS. Terlihat pada gambar 16. 


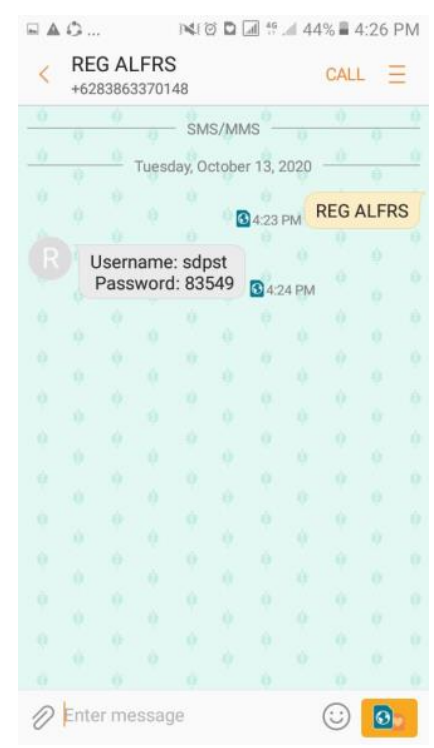

Gambar 16. Pengujian Request Akun

Dari hasil pengujian request akun yang dilakukan oleh user pada gambar 15 dapat disimpulkan sistem SMS Gateway yang dirancang menggunakan Gammu dan Rest API untuk melakukan proses autoreply berjalan dengan lancar dengan respon server $100 \%$. Hal itu ditunjukan dengan adanya reply langsung dari server berupa username dan password untuk login ke hotspot SMK Al-Farisi Leles.

\section{Perangkat yang Terhubung dengan Hotspot}

Setelalah user melakukan login ke hotspot menggunakan akun yang sudah diterima dari proses self request akun melalui SMS, maka selanjutnya administrator bisa dengan mudah mengontrol atau memonitoring user yang sedang aktif atau memakai layanan hotspot menggunakan aplikasi user manager. Hasil monitoring berjalan baik seperti pada gambar 17.

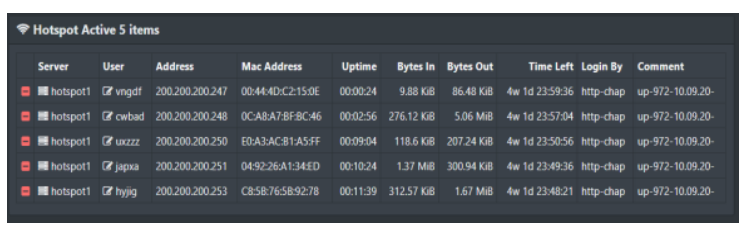

Gambar 17. Hotspot Active

Dari hasil pengujian yang terlihat pada gambar 16 terdapat lima user yang terhubung pada layanan hotspot. Pada proses ini juga administrator dapat melihat informasi tentang user seperti username yang digunakan, IP Address, MAC Address. Sehingga administrator dapat dengan mudah mengontrol atau me monitoring user yang terhubung dengan hotspot.

\section{KESIMPULAN DAN SARAN}

Penelitian ini mengintegrasikan antara sistem SMS Gateway dan aplikasi eksternal yaitu mikrotik monitoring hospot berbasis web yang disimpan di VPS server. Dengan self-service register user diimplementasikan tersebut untuk mempermudah pengelolaan dan monitoring user tanpa menggunakan radius server dan seorang administrator tanpa input user secara manual. Dari analisis dan pengujian pada user autentikasi berbasis SMS gateway di SMK Al-Farisi Leles, diperoleh beberapa kesimpulan, yaitu server mikrotik monitoring hotspot yang sudah terintegrasi dengan layanan SMS gateway menggunakan gammu, user dapat melakukan request account melalui SMS secara self-service tanpa menghubungi administrator. User hotspot bisa langsung digenerate secara otomatis dengan bantuan fitur dari server mikrotik monitoring hotspot yaitu generate user hotspot yang sudah dihubungkan dengan server mikrotik monitor hotspot. Dari sistem yang sudah diimplementasikan dan dilakukan pengujian oleh user dalam me-request akun hotspot melalui SMS, berjalan sesuai dengan yang diharapkan, terbukti dengan adanya autoreply yang didapat oleh user dengan tingkat keberhasilan $100 \%$

Dari hasil penelitian ini, implementasi user autentikasi berbasis SMS gateway dan mikrotik hotspot monitor, pengguna layanan internet di SMK Al-Farisi leles masih memerlukan handphone yang memiliki pulsa regular untuk menggunakan layanan hotspot di lingkungan sekolah, sehingga perlu dikembangkan menggunakan external server selain SMS Gateway, yaitu menggunakan API yang di integrasikan dengan Bot API email ataupun social media atau metode single sign on (SSO)[3].

\section{REFERENSI}

[1] Mulyanto, y., \& prakoso, s. b. (2020). Rancang Bangun Jaringan Komputer Menggunakan Sistem Manajemen Omada Controller pada Inspektorat Kabupaten Sumbawadengan Metode Network Development Life Cycle (NDLC): Jurnal Informatika, Teknologi dan Sains, 2(4), 223-233.

[2] M. Čihař, "Gammu and Wammu," 18 Agustus 2020. [Online] Available: https://wammu.eu/gammu/.

[3] Hakim, D. K., \& Nugroho, S. A. (2020). Implementasi Telegram Bot untuk Monitoring Mikrotik Router. Sainteks, 16(2).

[4] Mustofa, T. A., Sutanta, E., \& Triyono, J. (2019). Perancangan dan Implementasi Sistem Monitoring Jaringan Wi-Fi Menggunakan Mikhmon Online di Wisma Muslim Klitren Gondokusuman Yogyakarta. Jurnal Jarkom, 7(2), 65-76.

[5] Persada, G. N. (2019). Management Bandwidth Sekolah Menengah Kejuruan Negeri 2 Kota Tangerang Selatan Untuk Meningkatkan Layanan Akses Internet. Jurnal Ilmu Komputer, 2(1), 5-5.

[6] Mustofa, T. A., Sutanta, E., \& Triyono, J. (2019). Perancangan dan Implementasi Sistem Monitoring Jaringan Wi-Fi Menggunakan Mikhmon Online di Wisma Muslim Klitren Gondokusuman Yogyakarta. Jurnal Jarkom, 7(2), 65-76.

[7] A. Novianto, Komputer dan jaringan dasar, Jakarta: Erlangga, 2018. 
[8] Maulana, R. A., \& Sarmidi, S. (2018). PERANCANGAN JARINGAN HOTSPOT SERVER BERBASIS MIKROTIK DIGEDUNG KULIAH STMIK DCI TASIKMALAYA. Jurnal Manajemen dan Teknik Informatika (JUMANTAKA), 1(1).

[9] M. S. Natsir dan S. Alam, "Generate User Menggunakan Script Berbasis SMS Gateway," PROSIDING SEMINAR ILMIAH SISTEM INFORMASI DAN TEKNOLOGI INFORMASI, p. 249 - 258, 2017.

[10] Kuswanto, H. (2017). Sistem Autentikasi Hotspot Menggunakan Radius Server Mikrotik Router. INFORMATICS FOR EDUCATORS AND PROFESSIONAL: Journal of Informatics, 2(1), 43-50.

[11] A. H. Muttaqin, A. F. Rochim dan E. D. Widianto, "Sistem Autentikasi Hotspot Menggunakan LDAP dan Radius pada Jaringan Internet Wireless Prodi Teknik Sistem Komputer," jurnal Teknologi dan Sistem Komputer,, pp. 2338-0403, 2016.

[12] Handoko, L. B., \& Setiono, O. (2016). Rancang Bangun Sistem Hotspot Portable dengan OpenWRT. Sisfotenika, 6(2), 182-193

[13] Ceha, R., Prasetyaningsih, E., \& Bachtiar, I. (2016). Peningkatan Kemampuan Guru dalam Pemanfaatan Teknologi Informasi pada Kegiatan Pembelajaran. ETHOS: Jurnal Penelitian dan Pengabdian kepada Masyarakat, 131-138.

[14] Rinaldo, R. (2016). Implementasi Sistem Monitoring Jaringan Menggunakan Mikrotik Router OS di Universitas Islam Batik Surakarta. Emitor: Jurnal Teknik Elektro, 16(2), 56-63.

[15] Supendar, H. (2016). Implementasi Remote Site Pada Virtual Private Network Berbasis Mikrotik. Bina Insani ICT Journal, 3(1), 85-98. 